PART 3

THEORIZING POWER AND POSSIBILITY IN A COMPLEX WORLD 


\title{
8. RECOGNITION AND REDISTRIBUTION
}

\author{
Rethinking the Meaning of Justice in Adult Education
}

\section{CONCEPTUALIZING INEQUALITY}

This chapter discusses how adult education might contribute to the achievement of greater equality by drawing on case studies of three family literacy programs in Scotland. What is meant by equality can, however, be conceptualized in a number of ways. At one end of the spectrum is equality of opportunity where the focus is on the achievement of equality of access to, and participation in, education. The underlying assumption is that education is meritocratic and we live in a fair society that ensures that people will progress according to their ability (Gerwitz, 1998). From this perspective socio-economic adversity can be overcome by enabling access to a wide range of educational opportunities that individuals can take up or not according to their own motivation. At the other end is social justice where not only the economic but also the cultural aspects of justice are seen as vital. From this perspective remedying injustice requires not only the redistribution of opportunities but also equality of condition, which encompasses recognition of people's identities and their cultural diversity (Keddie, 2012).

Within this broad conceptualization of social justice there have been disagreements with some authors arguing that, rather than bringing the two aspects of recognition and redistribution together, the politics of redistribution and recognition are mutually exclusive alternatives. Writers such as Gitlin (1995) and Rorty (2000) argue that the focus on recognition serves to distract from the real issue of distributive injustice because concentrating on identity exaggerates difference rather than emphasizing commonalities. They suggest instead that recognition should be accorded to individuals rather than groups because focusing on what people share with "members of traditionally despised groups" (Rorty, 2000, p. 15) is more likely to promote broader political co-operation. Conversely, theorists such as Taylor (1992) and Honneth (2003) argue that ignoring differences and focusing exclusively on redistribution can serve to reinforce injustice by compelling minority groups and identities to 'fall in line' with the norms of the dominant group. Therefore, the struggles over a fairer distribution of opportunities, resources and rights should be thought of as struggles for recognition.

Nancy Fraser (2003), however, argues that issues of distribution and recognition interpenetrate. Though they do not fold neatly into one another, they interact causally 
and so it is important to be attuned to both dimensions. Treating every injustice as both economic and cultural, all must be assessed from both outlooks without reducing one to the other. Key to this approach is what Fraser calls the 'status model' of recognition. This model views misrecognition as a matter of social status, where: "patterns of disrespect and disesteem are institutionalized, for example, in law, social welfare, medicine, public education, and/or the social practices and group mores that structure everyday interaction" (Fraser, 1998, pp. 25-26). Fraser points out that some groups are subjected to both types of discrimination, particularly those from racial minorities, because they are "discriminated against in the labour market [whilst simultaneously] ... patterns of cultural value privilege some traits ... [meaning that they] are constructed as deficient and inferior others who cannot be full members of society" (Fraser, 2003, p. 23).

It is important to be clear about how we understand equality because its conceptualization strongly influences the policy structures, the pedagogical approaches and the expected outcomes used in adult education. I consider that Fraser's (2003) conceptualization of inequality is invaluable for exploring how education might contribute to social justice because its comprehensive view makes it more likely that its many dimensions, and their complex entanglement, can be interrogated and effectively responded to by researchers and practitioners. So, in the next section, I will use her concepts of 'redistribution' and 'recognition' to examine the impact of participation in family literacy education.

\section{REDISTRIBUTION AND RECOGNITION}

This section illustrates the impact of maldistribution and misrecognition on learning lives over the medium-term. It draws on interviews with family literacy learners, all women, that participated in three different projects in Scotland. All the projects were based in community settings in areas with high levels of unemployment: project 1 was on the outskirts of a large city in the West, project 2 in a large town in the East and project 3 in a small town in the North of Scotland. The participants in the projects were mothers of children who attended the primary schools in the area who had said they had literacy problems that they would like to work on in order to help themselves and their children. The research aimed to investigate the impact of participation on these learners' lives.

The interviews used an autobiographical approach where learners were asked to talk about their individual life histories, the circumstances in which they were currently situated and the impact of their participation in learning. All the projects were based in community settings and were selected because they represented good practice. I start with participants' previous experiences of school to illustrate how these had influenced their current views of themselves and their ability to learn and then move on to consider the impact of their programs. 


\section{Schooling}

Many participants emphasized the maldistribution of the opportunities available to them. For example, some learners, slower than the 'brighter' children in large classes, reported that they simply dropped off the teachers' radar and did not receive the attention that they required. One reflected: "I liked my first school, but the other kids were better than me ... The classes were too big, there wasn't enough time to learn what I should have". Another remembered having difficulties at primary school. She was very slow at reading but did not feel that the teachers noticed and she thought that they were: "more interested in the ones that could get on ... They sort of just left me to one side".

In addition, some people remembered being bullied and this affected their ability to learn which led a number to stop participating in their schools either by being physically absent or not paying any attention even if they were there. For example: "I was bullied so much ... I didn't take anything in and I just used to sit and doodle all day". Another learner's memory of education was dominated by the impact of bullying teachers: "if you answered a question and got it wrong you were punished so I tried to avoid answering anything".

One learner, however, described school as "a haven [that] provided a chance to escape from the problems at home" where she was bullied by her older brothers. Few learners were able to identify a teacher who had recognized their capabilities and invested time in supporting them which research has shown has a positive impact on attainment (Bynner \& Joshi, 2002). Moreover, hardly any reported that their parents had helped them with homework or discussed their progress with teachers and many lacked a stable and supportive family environment. In addition, many said that they had lived in poverty where "there wasn't enough money to go round" and this impacted not only on their academic achievements in their school years but also on their attainment in adulthood (Schoon \& Bynner, 2003).

Not achieving at school had a lasting effect on recognition through its impact on individuals' self-esteem. For example, one participant said "I am not very academic; I have not got a lot of confidence in myself. I scraped through, only got one 'O level'. I am not brainy". As Charlesworth (2000, pp. 243-244) has argued: "being told that one is not clever is ... not something about which one can achieve indifference ... Thus we end up with people defined ... as 'useless', unable, stupid; lacking in the dignities given to the privileged".

These learners' stories illustrate that the educational opportunities open to them were not equal and so they did not benefit from their schooling to the extent that their more advantaged peers did. Clearly many experienced maldistribution in terms of their access to good quality education as well as misrecognition because their teachers, their peers and, in some cases, their parents constructed their skills and experiences as inferior.

One driver of these inequities is the adoption of particular assessment and evaluation regimes. A key influence on how these regimes are implemented is 
the statistics that are gathered and analyzed by the Organisation for Economic Cooperation and Development (OECD) for its international comparisons (Meyer \& Benavot, 2013). The league tables produced by these international comparisons, such as the Programme for the International Assessment of Adult Competencies (PIAAC) (OECD, 2013), are underpinned by an equality of opportunity approach. This is because the focus of the comparison is on the distribution of access to, and the successful outcomes of, participation in education (Lingard et al., 2014). As a result, attention is paid only to outcomes related to economic growth such as qualifications and not to an education that adapts to the needs of all learners.

So, rather than an education that is inclusive because it recognizes people's social and cultural backgrounds, we end up with one that is driven by efficiency and economic growth. Moreover, the underlying structural and socio-economic factors that produced these unequal outcomes in the first place are neglected (Connell, 2012). It is clear then that learners in these family literacy programs had neither experienced redistribution nor recognition at school but did their later experiences in the family literacy programs change this?

\section{Learning in Family Literacy Programs}

Research shows that participating in family literacy programs can lead to positive changes in both parents and children (Forté, 2013), but not all programs are empowering. This is because if it is not recognized that "families' lives are deeply shaped by racial, class, and migrant inequality" (Baquedano-López et al., 2013, p. 172) then schools reproduce these inequalities by using deficit perspectives that reinforce parents' negative views of themselves. Practices in schools are strongly connected to issues of ideology and power that result in the view that parents should fit into the dominant culture rather than that schools should be engaging with the diversity of parents. For example, Moll (2005, p. 280) argues that there is a focus on "how parents can accommodate to the routine of schooling, [but not on] how they can get the school to accommodate their needs, conditions, and desires". To reverse this assumption requires a view that all parents and communities have important 'funds of knowledge' (González et al., 2005) to contribute to education and are 'knowledge-rich' rather than 'knowledge-poor'. Therefore, pedagogies that build on, rather than denigrate, the expertise of participants and start from their own goals are more likely to lead to greater equality (Barton et al., 2007).

The programs studied did support parents to fulfill their aspirations and further develop their own expertise as their children's first educators. One important aspect of this was the use of authentic assessment situated in real life contexts, which is done with, not to, participants. Assessment was based on the extent to which participants had been able to change their literacy practices from their own baselines - the distance that they had travelled. People's learning is normally assessed through the use of standardized outcome-based methods so this different approach was empowering 
because it enabled participants to have an equal say in the direction their learning should take based on their own goals.

As a result of these approaches many learners talked about the way they thought about themselves: "here they build you up and help you to think positively"; "the staff treat you like a person". Working together was important because: "being part of the group has helped me to keep going even when things were really difficult at home" and "the others knew I didn't like writing on the flip-chart because my spelling isn't good but with their encouragement I did it and after that I felt really proud of myself". In addition, because participants felt their knowledge of their children was valued, they considered that "education was probably something that I could go back to as an adult. It just made me see things in a different light. Everything wasn't awful".

Others spoke about being respected: "in this program you're respected as a person that has a lot of knowledge that others can learn from". This respect was created through learners feeling that their issues, circumstances and concerns were both acknowledged and valued. For example: "here you don't get judged on what you can't do. Instead the tutors help you to find what you can do". Another said that she "used to just go to the shops and back to the house but now I'm out doing lots of things and I'm not isolated any more". Learners found that their progress made them feel differently about what they could achieve: "I felt more confident. It made me a more confident parent with the girls ... [and] in what I could achieve myself".

Using a 'funds of knowledge' pedagogy that focused on what learners could do increased confidence: "the tutor helped me to work out what I could do and then, once I was happy about that, I worked on what I couldn't do". It also involved participants valuing their own skills. For example, one found that her ability to tell stories from her Traveller culture meant that she had a much better oral memory than other people but this skill had been unacknowledged before she joined the group. For many being part of a group helped with learning: "you're in with the group so you get involved ... we've worked together on making books for the children and it's very satisfying". A number of learners suggested that it was the tutors that made an impact: "she [tutor] brings stuff out of me and stretches my mind" and "it motivates me to really try because the tutors are working so hard".

An atmosphere had been created where learners were treated with respect within relationships of trust (Feeley, 2014). Having a caring ethos not only enabled participants' strengths to be recognized but also helped to create supportive social networks (Prins, Tosso, \& Schafft, 2009, p. 336). Participants in these programs said that they had changed their dispositions to learning and altered their practices partly because of these positive caring relationships. For example: "the staff are always available to listen to your questions and because of this you feel able to ask even if you think it might be a silly question". So, most of the learners had worked through previous negative learning identities and were much more engaged in learning so that, as one put it: "now I feel that what I know is of value then I'm 
much more willing to try anything whereas before I just used to say to myself "you can't do it"'.

There is evidence here then that participation in the programs brought about changes in the recognitional aspect of Fraser's (2003) model of social justice and, as a result, there are also examples of the redistributive aspect. The learners clearly saw the recognition of their experiences as a step towards greater redistribution because, for example, "the tutors trusted us with important tasks like creating the children's book so that made me feel that I could get a job where I would also need to be trusted". 'Because the program developed my confidence I went on to apply for college and now I'm at university and have a new career in front of me'. Most of the changes that the learners experienced in the employment opportunities that were open to them were quite modest but this does demonstrate, as Fraser has argued, that the recognitive and redistributive aspects of social justice fold into one another and action needs to be taken in both spheres simultaneously to obtain greater equality.

\section{RETHINKING SOCIAL JUSTICE}

So far, this chapter has considered how participants in family literacy programs have experienced two of the dimensions of social justice namely redistribution and recognition. Fraser also proposed a third dimension that she named 'participatory parity', because it focuses on equality of participation in decision making. She argued that this concept "sets the procedures for staging and resolving contests in both the economic and the cultural dimensions" (2008, p. 17). Its achievement requires that individuals participate on an equal footing in processes that give them a voice in public deliberations and democratic decision-making particularly over issues that directly affect them. So, this aspect of social justice involves making social arrangements that mean that all people are enabled to participate as equals in social life. It is concerned about how injustices should be remedied and requires the critical interrogation of the ways in which equity is understood and pursued. This means that there needs to be a revaluation of the knowledge, skills and understanding of non-dominant groups so that rather than providing an education that is considered to be good for them instead we need to ensure that the curriculum is built around their views.

In the projects I researched curriculum approaches were developed that operated to support the decision making of the participants. The curriculum was based on the learners' concerns and aspirations about their own and their children's learning and relationships to their teachers so that education was seen as a co-operative activity involving respect and trust. The teaching was based on a group process, where the tutor and students learnt together, beginning with the concrete experience of the participants, leading to reflection on that experience in order to affect positive change. As a result, the participants were able to add new and different knowledge and become the subjects of learning rather than the objects of educational interventions that were supposed to be good for them. Learning then became a shared endeavor between tutors and students, a two-way, rather than a one-way, process. 
This approach provided a real incentive for learning because it concentrated on what really mattered to the participants. As a result, learners commented that they now saw some of their earlier assumptions differently. For example: "I see how my school teachers tried to put me down and now I'm involved in a family literacy project so that I can help other parents to be a bit more challenging". Another example was from the only male in one of the groups who acknowledged that he had come to see that he had a very gendered approach to his life. "In my family the girls did all the housework and I was just allowed to go out with my friends and I kind of carried this over in my family life too but now I'm the one at home looking after the kids I can see how sexist I used to be". These examples show that the learners became more reflexive about their experiences and had found ways to reconstitute previously internalized injustices. As one participant put it: "learning can open your eyes to what you are good at and means that you are willing to take risks in trying to make changes both for your children but also in the community". Participants had become more confident about challenging the social injustices they had experienced: for example, 'I speak out more at home if I think things are not fair' and 'I'm more confident in challenging the teachers' views about my child".

Engaging in participatory processes in implementing and evaluating programs, being in a safe and open space to discuss, dissent and agree on the best courses of action, and integrating different views, fosters dialogue and enables the recognition of difference and diversity (Baquedano-López et al., 2013). This form of education meant that participants were enabled to take these experiences of equality of decision-making and participation into their families and communities. In addition, a few learners were able to participate in the broader political arena, where the power imbalances and negative discourses they experienced could be most effectively challenged. For example, participants in one project reported that they were taking action to tackle racism in their community as a result of shared experiences in their group. They commented:

Kurshid told us about how bad the racist graffiti that was all over our community made her feel and so we saw that we should all do something about it. We had got a lot of strength from working together in this group and so we are challenging the Council about why they haven't done anything to clean it up. It's hard work as they aren't very responsive but we are determined that we will just carry on until they agree to our demands.

For this group then, an issue that they had come to understand through sharing and reflecting on their experiences together had resulted in action that focused on the political level. Their action was driven by equity concerns enacted in solidarity that gave them a voice in resolving issues that were located in their community but had far wider implications politically. Thus a conceptualization of social justice that is based on 'participatory parity' can and should be a goal for adult education if it is to prioritize the voices of those that had previously been excluded. 


\section{CONCLUSION}

In this chapter I have argued that the dominant 'equality of opportunity' conceptualization of equity that assumes that we live in a fair society is seriously flawed. Instead, I have used the social justice lens offered by Fraser (2008) and her concepts of recognition, redistribution and participatory parity, to think through both the enduring inequalities experienced by learners and also the democratic possibilities opened up to them. In particular, I have shown the importance of using pedagogical approaches that build on the knowledge that participants bring as well as using a distance-travelled method of assessing progress based on the learners' own goals. This social justice approach to adult education has led to positive changes in the recognitive sphere whereas learners had previously experienced institutionalized patterns of disrespect and lack of esteem in both the education system and in their everyday interactions. I have also highlighted how issues of distribution and recognition interpenetrate causally because learners have pointed out how increases in their self-confidence, brought about by being treated with respect, have enabled them to go on to further and higher education or to gain employment thus enabling some action in challenging economic discrimination. Creating a democratic curriculum so that learners are seen as having the right to make decisions about their lives has led to action at the family, community and political levels so changes have also been made in moving towards more equity in this sphere. All this adds up to an education that shifts the focus onto the systemic and contextual factors that operate to limit democratic participation whilst simultaneously ensuring that individuals' personal and social circumstances do not interfere with their potential.

A great deal of research has shown that there have been dramatic rises over the last decade in inequality in incomes and wealth that have negative consequences for society as a whole (Piketty, 2014). Set alongside this the evidence presented here that participation in family literacy programs does lessen social injustices may seem trivial. However, educating in socially just ways through creating learning environments that enable participants to have the necessary material and human resources to achieve their goals, to have their cultural experiences respected and their views acted upon is an important step on the way towards achieving greater social justice.

In the light of this there are a number of implications for adult education arising from using the lens of social justice rather than the dominant equality of opportunity lens. First it provides a way of conceptualizing the impact of participating in literacy programs that goes beyond the usual assessment method of only measuring increases in narrow literacy skills. This is because it demonstrates the importance of social justice as a positive outcome of participation. Second this perspective challenges the individual deficit view of literacy learners. Instead the focus is on the democratic assumption that people are equal in a variety of different ways but social structures operate to deny social justice to some whilst privileging powerful others. Third participation in democratic decision-making is foregrounded as an important 
outcome of learning and thus enables more active challenges to contest at both the economic and cultural levels leading to greater participatory parity. Whilst education is not a panacea for all social ills and cannot alone compensate for the inequities of society, I have demonstrated that it can make a difference in creating more equitable conditions for those that have already experienced the greatest injustice.

\section{REFERENCES}

Baquedano-López, P., Alexander, R., \& Hernandez, S. (2013). Equity issues in parental and community involvement in schools. Review of Research in Education, 37, 149-182. doi:10.3102/0091732X12459718

Barton, D., Ivanic, R., Appleby, Y., Hodge, R., \& Tusting, K. (2007). Literacy, lives and learning. London: Routledge.

Bynner, J., \& Joshi, H. (2002). Equality and opportunity in education: Evidence from the 1958 and 1970 birth cohort studies. Oxford Review of Education, 28(4), 405-425. doi:10.1080/0305498022000013599

CERI. (2008). Teaching, learning and assessment for adults: Improving foundation skills. Paris: OECD Publishing.

Charlesworth, S. J. (2000). A phenomenology of working class experience. Cambridge: Cambridge University Press.

Connell, R. (2012). Just education. Journal of Education Policy, 27(5), 681-683.

Feeley, M. (2014). Learning care lessons: Literacy, love care and solidarity. London: Tufnell Press.

Forté, K. S. (2013). Educating for financial literacy: A case study with a sociocultural lens. Adult Education Quarterly, 63(3), 215-235.

Fraser, N. (1998). Heterosexism, misrecognition and capitalism: A response to Judith Butler. New Left Review, 228, 140-149.

Fraser, N. (2003). Social justice in the age of identity politics: Redistribution, recognition, and participation. In N. Fraser \& A. Honneth (Eds.), Redistribution or recognition? A political-philosophical exchange (pp. 7-109). London: Verso.

Fraser, N. (2008). Scales of justice: Reimagining political space in a globalising world. Cambridge: Polity Press.

Gewirtz, S. (1998). Conceptualising social justice in education: Mapping the territory. Journal of Education Policy, 13(4), 469-484.

Gitlin, T. (1995). The twilight of common dreams: Why America is wracked by culture wars. New York, NY: Metropolitan Books.

González, N., Moll, L., \& Amanti, C. (2005). Funds of knowledge: Theorizing practices in households, communities and classrooms. Mahwah, NJ: Erlbaum.

Honneth, A. (2003). Redistribution as recognition: A response to Nancy Fraser. In N. Fraser \& A. Honneth (Eds.), Redistribution or recognition? A political philosophical exchange (pp. 110-197). London: Verso.

Keddie, A. (2012). Educating for diversity and social justice. London: Routledge.

Lingard, R., Sellar, S., \& Savage, G. C. (2014). Re-articulating social justice as equity in schooling policy: The effects of testing and data infrastructures. British Journal of Sociology of Education, 35(5), 710-730.

Meyer, H.-D., \& Benavot, A. (2013). Pisa, power and policy: The emergence of global educational governance. Oxford: Symposium Books.

Moll, L. (2005). Reflections and possibilities. In N. González, L. Moll, \& C. Amanti (Eds.), Funds of knowledge: Theorizing practices in households, communities and classrooms (pp. 275-287). Mahwah, NJ: Erlbaum.

OECD. (2013). OECD skills outlook 2013: First results from the survey of adult skills. Retrieved from http://www.oecd.org/site/piaac/Skills\%20volume\%201\%20\%28eng\%29--full\%20v8--eBook\%20\% 2801\%2010\%202013\%29.pdf 


\section{TETT}

Piketty, T. (2014). Capital in the twenty first century. London \& Cambridge, MA: Harvard University Press.

Prins, E., Toso, B. W., \& Schafft, K. A. (2009). "It feels like a little family to me" social interaction and support among women in adult education and family literacy. Adult Education Quarterly, 59(4), 335-352. doi:10.1177/0741713609331705

Rorty, R. (2000). Is "cultural recognition" a useful notion for Leftist politics? Critical Horizons, 1(1), $7-20$.

Schoon, I., \& Bynner, J. (2003). Risk and resilience in the life course: Implications for interventions and social policies. Journal of Youth Studies, 6(1), 21-31.

Taylor, C. (1992). Multiculturalism and 'the politics of recognition'. Princeton, NJ: Princeton University Press. 